\title{
Volatilidade Fiscal e Crescimento: Uma Análise para os Estados Brasileiros
}

\author{
Alexsandro Ordonez ${ }^{1} \mid$ Ricardo Batista Politi ${ }^{2}$ \\ ${ }^{1}$ Graduação em Ciências Econômicas pelo Centro Universitário FECAP. E-mail: alexsandro.mori@gmail.com \\ ${ }^{2}$ Professor Adjunto da Universidade Federal do ABC. E-mail: rbpoliti@gvmail.br
}

\begin{abstract}
RESUMO
Este trabalho investiga como a volatilidade do ciclo econômico e as oscilações dos investimentos públicos e das variáveis fiscais afetam o crescimento das unidades federativas brasileiras para o período de 1997 até 2016. Em particular, são estimados os efeitos das volatilidades das despesas, receitas e estoque da dívida sobre o crescimento econômico. Os resultados sugerem que o aumento das volatilidades dos investimentos estaduais e da dívida são prejudiciais ao crescimento de longo prazo em todas as localidades. Adicionalmente, essas relações são investigadas para dois grupos de estados com diferentes tamanhos. Os resultados por grupos indicam que oscilações nas variáveis fiscais produzem um efeito negativo e maior sobre o crescimento dos estados menores, enquanto a volatilidade do investimento público está associada ao menor crescimento econômico nos estados maiores.
\end{abstract}

\section{PALAVRAS-CHAVE}

Volatilidade fiscal, Crescimento econômico, Tamanho de governo

\section{Fiscal Volatility and Economic Growth: Analysis for Brazilian States}

\begin{abstract}
This paper investigates how the volatility of economic activity, public investment and fiscal variables affects the growth of Brazilian federative units for the period from 1997 to 2016 . In particular, it estimates the effects of fluctuations in expenses, revenues and public debt on economic growth. Results suggest that increases in local public investment and debt volatilities are detrimental to long-term growth in all locations. Additionally, these relationships are investigated for two groups of states with different sizes. Results by groups indicate that fluctuations in fiscal variables have a negative and greater effect in smaller states, while in larger states the volatility of public investment is associated with lower economic growth.
\end{abstract}

\section{KEYWORDS}

Fiscal volatility, Economic growth, Government size

\author{
CLASSIFICAÇÃO JEL \\ R11, H50, E62
}




\section{Introdução}

Um tópico importante na literatura macroeconômica é a relação entre instabilidade dos ciclos econômicos e seus efeitos sobre o crescimento do Produto Interno Bruto (PIB) de longo prazo. De fato, modelos que assumem a irreversibilidade do investimento (Pindyck, 1990; Pindyck e Solimano, 1993) apontam que a incerteza e a instabilidade podem afetar negativamente o crescimento via queda dos investimentos. Diferentemente dos modelos de ciclos de negócios de Lucas (1987), nos quais praticamente não existe interação entre oscilações nos ciclos econômicos e crescimento de longo prazo, novas teorias sobre o crescimento sugerem que ele é suscetível a políticas macroeconômicas nas áreas fiscal, monetária e cambial (Furceri, 2010; Pindyck e Solimano, 1993).

Em particular, a literatura recente tem discutido o efeito de políticas fiscais sobre a trajetória do PIB. Políticas fiscais expansionistas podem suavizar as flutuações econômicas e impulsionar o crescimento no longo prazo, enquanto políticas fiscais menos rígidas, por sua vez, podem ser fontes adicionais de instabilidade, aumentando a flutuação das variáveis econômicas (Ramey e Ramey, 1994; Afonso e Furceri, 2010; Furceri, 2010). Portanto, é importante discutir o papel da política fiscal na redução de oscilações nos ciclos da atividade econômica.

Mais recentemente, diversos autores têm mostrado como a política fiscal cíclica pode contribuir para aumentar a volatilidade dos ciclos econômicos (Ramey e Ramey, 1994; Afonso e Furceri, 2010; Fatás e Mihov, 2006) encontram evidências que políticas fiscais mais rígidas reduzem não somente a volatilidade econômica, mas também os impactos de uma política fiscal com efeitos expansionistas no crescimento econômico. Os autores encontram evidências de que o primeiro fator é predominante. Esse resultado é semelhante ao encontrado por Furceri (2007) para países da Organização para a Cooperação e Desenvolvimento Econômico (OCDE).

Esse referencial analítico parece ser bastante adequado para discutir o crescimento econômico dos estados no Brasil. Júnior e Aguiar (2018) mostram que a situação fiscal dos estados piorou a partir da crise 2008 com a queda do volume de receitas e a dificuldade em reduzir os gastos públicos, gerando déficits fiscais crescentes nos anos seguintes. Ainda segundo os autores, parte do ajuste fiscal nesses estados se deu a partir de cortes nos investimentos públicos, os quais apresentaram grandes oscilações anuais no período analisado.

Por conta da grave situação fiscal da maior parte dos estados brasileiros, sobretudo a partir do ano de 2010, muito se discute sobre como as variações na capacidade de investimento dos governos locais ou do tamanho dos gastos do governo afetam o crescimento econômico. Se, por um lado, existe evidência empírica que reforça o papel do investimento público no crescimento econômico, por outro, diversos estudos indicam que o tamanho do gasto público costuma estar negativamente associado à expansão da economia (Afonso e Furceri, 2010). 
Assim, o objetivo deste artigo é investigar como a volatilidade da política fiscal dos estados afeta a trajetória de crescimento dessas localidades no longo prazo. São analisados dados da trajetória do crescimento econômico das 27 Unidades Federativas (UF) brasileiras para os anos de 1997 até 2016. Esse recorte temporal é relevante porque compreende um período de grande expansão (de 2004 a 2008) e outro de importante declínio (de 2014 a 2016) da atividade econômica. Adicionalmente, a situação fiscal dos estados no período delimitado, com déficits constantes e aumento do endividamento, aumenta o interesse em compreender os efeitos da volatilidade nas variáveis fiscais, como despesas, receitas e estoque da dívida, sobre o crescimento.

Com base na metodologia proposta por Afonso e Furceri (2010) e Furceri (2010), as variáveis referentes a despesas, receitas e dívida de governo e suas respectivas volatilidades são incorporadas à função de crescimento de longo prazo. Uma novidade deste trabalho em relação à literatura anterior é que os efeitos das oscilações nas variáveis fiscais são estimados para grupos de estados classificados de acordo com o PIB per capita. Para o grupo de estados menores, os resultados sugerem que oscilações nas variáveis fiscais são mais prejudiciais ao crescimento de longo prazo em relação à amostra total. Já para os estados maiores em termos econômicos, os resultados indicam que o efeito negativo do aumento da volatilidade do investimento público estadual é muito maior em comparação com a amostra total. Esses resultados são importantes, pois assinalam que os efeitos das oscilações econômicas dependem das características das localidades, como tamanho da economia, e que localidades menores tendem a sofrer mais com oscilações na política fiscal.

Além desta introdução, este artigo aborda o tópico crescimento econômico e volatilidade em cinco seções. Na próxima seção, é feita uma breve justificativa para o tema. A seção três descreve a metodologia aplicada. Na seção quatro, é apresentado o contexto das finanças públicas estaduais a partir dos dados do período. Já a seção cinco apresenta os resultados. Por fim, a seção seis apresenta a conclusão.

\section{Atividade Econômica e Volatilidade}

Esta seção revisa a literatura que investiga como volatilidade e ciclo de atividade econômica impactam no crescimento. Os principais artigos descritos são apresentados no Quadro 1. Os resultados desses estudos apontam que as volatilidades (da atividade econômica e do orçamento) são importantes para compreender o crescimento econômico e frequentemente estão negativamente associadas a ele.

Entre os primeiros autores a mostrar o efeito da volatilidade da atividade econômica sobre o crescimento, figuram (Ramey e Ramey, 1994). Utilizando uma amostra com 92 países, os autores encontram evidências de que países com maior volatilidade apresentam menor crescimento. Além dessa associação negativa entre crescimento e volatilidade, diversos outros artigos abordam quais políticas macroeconômicas podem mudar a volatilidade do PIB e afetar o crescimento econômico. 
Guadro 1. Estudos sobre o Impacto da Volatilidade sobre o Crescimento Econômico

\begin{tabular}{|c|c|c|c|}
\hline Autor(es) & Ano & Modelo Econométrico & Variáveis Relevantes \\
\hline Ramey e Ramey & 1995 & $\begin{array}{l}\text { Dados em Painel (efeito } \\
\text { fixo) }\end{array}$ & $\begin{array}{l}\text { Volatilidade (-); Investimento (+); Crescimento } \\
\text { populacional (-) }\end{array}$ \\
\hline Furceri & 2008 & $\begin{array}{l}\text { Dados em Painel (efeito } \\
\text { fixo) }\end{array}$ & $\begin{array}{l}\text { Volatilidade (-); PIB per Capita Inicial (-); } \\
\text { Investimento(+); Crescimento populacional(-) } \\
\text { Volatilidade do Investimento (-); Volatilidade } \\
\text { dos Gastos do Governo (-); Volatilidade da in- } \\
\text { flação (-); Volatilidade da taxa de câmbio (-); } \\
\text { Gastos do Governo (-) }\end{array}$ \\
\hline Afonso e Furceri & 2010 & $\begin{array}{l}\text { Dados em Painel (efeito } \\
\text { fixo) }\end{array}$ & $\begin{array}{l}\text { Volatilidade (-); Investimento (+); Abertura co- } \\
\text { mercial (+); Capital Humano (+); Crescimento } \\
\text { Populacional (-); Receitas (-); Despesas (-); Im- } \\
\text { postos indiretos (-); Contribuições sociais (-); } \\
\text { Subsidios (-); Consumo do Governo (-) }\end{array}$ \\
\hline Afonso e Jalles & 2012 & $\begin{array}{lccc}\text { Dados } & \text { em } & & \text { Painel } \\
\text { (Efeito } & \text { Fixo) } & \text { e } & \text { GMM- } \\
\text { SYS } & & & \end{array}$ & $\begin{array}{l}\text { Comércio Internacional (+); Educação (+); In- } \\
\text { vestimento(+); Volatilidade das Receitas (-); } \\
\text { Gastos de Governo (-); Volatilidade de Gastos } \\
\text { do Governo (-) }\end{array}$ \\
\hline
\end{tabular}

Fonte: Elaborado pelos autores.

Para Pindyck e Solimano (1993), um aumento da incerteza associado à maior volatilidade do preço da moeda (inflação) afeta a taxa de retorno do capital e influencia negativamente o total dos investimentos. Al-Marhubi (1998), com uma amostra de 78 países para o período 1965 a 1985, mostra que um aumento da volatilidade da inflação é negativamente associado ao crescimento econômico. De maneira diferente, Sarel (1996) não encontra essa associação em países com inflação moderada.

Outros autores discutem os efeitos da volatilidade da taxa cambial como fonte de instabilidade para o crescimento por meio da redução do comércio internacional (Frankel e Rose, 2002). Segundo Aghion et al. (2009), que confirmam que a instabilidade cambial apresenta um impacto negativo sobre o crescimento, o efeito seria mais forte sobretudo em países com mercado de capitais menos robustos e que enfrentam restrições no financiamento de crédito para as firmas.

Mais importante para esta pesquisa, uma ampla parte da literatura discute os efeitos da volatilidade da política fiscal sobre o crescimento econômico. Evidência empírica anterior sugere que políticas fiscais mais restritivas tendem a produzir melhores resultados em termos de crescimento econômico. Alesina e Wacziarg (1998), por exemplo, investigam os efeitos de regras orçamentárias sobre os entes federativos dos Estados Unidos da América (EUA) e concluem que essas regras reforçam a disciplina fiscal dos estados sem efeitos adicionais sobre a volatilidade do produto. Fatás e Mihov (2006), primeiro com uma amostra dos estados dos EUA e, depois, com uma amostra de 91 países, concluem que políticas fiscais muito ativas provocam maior volatilidade na produção, com prejuízo para o crescimento. Por outro lado, concluem os 
autores, política fiscal mais rígida age no sentido contrário, diminuindo as oscilações e produzindo efeito positivo sobre a taxa de expansão da economia.

Ainda, pesquisa anterior indica que politicas fiscais mais estáveis estariam associadas ao maior crescimento econômico. Políticas fiscais menos flexíveis estariam associadas a um ambiente de maior estabilidade e menos incerteza em relação à sustentabilidade da dívida pública e assim tenderiam a impactar positivamente o crescimento econômico de longo prazo (Afonso e Jalles, 2012). Em contrapartida, a menor previsibilidade da política fiscal poderia gerar mais oscilações na economia e afetar negativamente o crescimento no longo prazo (Furceri, 2010).

Em especial, Afonso e Furceri (2010) assinalam a importância de considerar duas medidas de atividade fiscal nessa discussão: o tamanho relativo do governo, em termos de receita e despesa como proporção do PIB, e a volatilidade desses componentes do orçamento do governo. Com essa metodologia, os autores examinam os efeitos do tamanho do orçamento do governo e a volatilidade dos seus componentes sobre o crescimento da economia para uma amostra de países da União Europeia e outra amostra com países da Organização para a Cooperação e Desenvolvimento Econômico (OCDE). Os resultados indicam que tanto o tamanho de governo como a volatilidade fiscal prejudicam o crescimento econômico nesses países. Segundo os autores, o aumento de um ponto percentual na parcela de receitas em relação ao PIB provoca um decréscimo de aproximadamente 0,12 pontos percentuais no crescimento. Analogamente, um aumento da volatilidade nos componentes fiscais desestimula a expansão da atividade econômica (Afonso e Furceri, 2010).

De maneira similar, Poterba (1994) ressalta a importância de regras fiscais e do controle orçamentário sobre o crescimento econômico para todos os estados dos EUA. Em seu estudo, o autor conclui que, quanto maior a capacidade das instituições em regrar e limitar o déficit passado de gestão na esfera estadual, maiores as chances destes entes federativos lidarem com a incerteza e, consequentemente, com a volatilidade dos componentes de crescimento econômico. Alt e Lowry (1994) vão na mesma direção de Poterba (1994) e assinalam que os controles sobre a discricionariedade dos gastos públicos são importantes não somente para que estados dos EUA lidem com a incerteza, mas também para que estes se recuperem com maior rapidez de eventuais flutuações.

Adicionalmente, alguns autores consideram a importância do tamanho do país na análise. Segundo Furceri e Ribeiro (2008), países pequenos em termos populacionais tendem a sofrer mais com os impactos da volatilidade sobre seu crescimento econômico. Já Alesina e Wacziarg (1998) mostram que países maiores em termos de consumo per capita apresentam menor tamanho de governo e atribuem esse resultado a ganhos de escala no provisionamento público. Desse modo, em termos de crescimento, uma política fiscal estável parece ser mais importante do que uma política expansionista que incorra em maior tamanho de governo. Porém, esses resultados parecem variar entre localidades, dependendo do tamanho da economia e do nível de 
desenvolvimento local. Como a condução da política cambial e a da política monetária pertencem ao governo central, no caso dos governos locais, é importante compreender como estados com diferentes tamanhos e diferentes estágios de desenvolvimento reagem aos ciclos econômicos e às oscilações dos seus orçamentos.

Esta seção apresentou a revisão da literatura que investiga a relação da volatilidade dos ciclos econômicos e do orçamento com o crescimento econômico, frequentemente negativamente relacionados. A próxima seção descreve a estratégia metodológica utilizada para investigar esses efeitos sobre as unidades federativas no Brasil.

\section{Abordagem Metodológica}

O principal objetivo deste trabalho é estimar funções de crescimento econômico a partir de dados orçamentários de todas as 27 Unidades Federativas da União, no período de 1995 a 2016. Desse modo, as relações entre crescimento econômico e oscilações na política fiscal podem ser representadas pela função (1) (Afonso e Furceri, 2010):

$$
g_{i t}=\alpha+\beta_{0} y_{i 0}+\beta_{1} X_{i t}+\phi \text { Governo }_{i t}+\rho \sigma_{i t}^{\text {Governo }}+\eta_{t}+\nu_{i}+\epsilon_{i t}
$$

onde o índice $\mathrm{i}(\mathrm{i}=1, \ldots, 27)$ denota cada unidade da federação e o índice t retrata os períodos de tempo da amostra. A medida de crescimento econômico para cada estado e Distrito Federal (DF) é dada pela diferença entre os logaritmos da variação per capita do PIB, conforme indicado pela função (2):

$$
g_{i t}=\operatorname{Ln}\left(\frac{Y_{i t}}{Y_{i t-1}}\right)=\operatorname{Ln}\left(Y_{i t}\right)-\operatorname{Ln}\left(Y_{i t-1}\right)
$$

A matriz de variáveis $X_{i t}$ contém as variáveis de controle utilizadas nesta especificação e que seguem o referencial analítico apresentado no Quadro 1. Foram utilizados como controles o capital humano, medido como a média de anos de estudo de maiores de 21 anos; o crescimento populacional, medido também como variável de crescimento logarítmico; e a variável investimento público estadual, medida como proporção do PIB de cada estado. Ademais, a variável PIB inicial per capita $\left(y_{i \theta}\right)$ é uma variável de controle utilizada no início de cada agrupamento no tempo como uma medida de convergência temporal das unidades federativas.

O parâmetro $\nu_{i}$ é o termo fixo inerente a cada estado e $\eta_{t}$, o termo temporal. A variável Governo, por sua vez, tem como finalidade medir os impactos de variáveis fiscais sobre o crescimento econômico dos estados. Ou seja, nesta análise0 são classificadas como medidas de políticas fiscais de governo as receitas ou as despesas das unidades federativas, ou ainda algumas despesas específicas associadas à maior atividade econômica, como gastos em infraestrutura urbana e transporte. 
O termo designado por $\sigma_{i t}^{\text {Governo }}$ representa o vetor de volatilidades abordadas na função (1). A primeira é a volatilidade associada ao crescimento do PIB e a segunda é relacionada à volatilidade fiscal dos componentes de Governo. Todas as medidas de volatilidade são construídas por meio do cálculo do desvio-padrão para um período de quatro anos sobre o componente cíclico da série de crescimento obtido por meio do uso do filtro de Hodrick e Prescott (1980), conhecido como filtro HP. O filtro HP (HODRICK; PRESCOTT, 1980) extrai a tendência, aqui considerada como um elemento estocástico e não correlacionado com o ciclo econômico, a qual pode ser entendida como um simples exercício de minimização, em que:

$$
\min _{\left[\tau_{t}\right]_{t=1}^{T}}\left[\sum_{t=1}^{T} c_{t}^{2}+\lambda \sum_{t=2}^{T}\left(\left(\tau_{t+1}-\tau_{t}\right)-\left(\tau_{t}-\tau_{t-1}\right)\right)\right]^{2}, \lambda>0
$$

Na função (3), o termo $T$ é o tamanho da amostra utilizada e $\lambda$ (lambda) é o parâmetro de suavização da série. A ideia é minimizar o efeito do termo de tendência $\tau$ sobre o componente cíclico $c$. O parâmetro de suavização utilizado na especificação principal é de 6,25. Esse parâmetro segue Afonso e Furceri (2010) e Afonso e Jalles (2012) para o caso de observações temporais com período anual. Resultados com especificações alternativas alternando o parâmetro de suavização e o filtro da série indicam que os resultados são robustos a outras escolhas de medida de volatilidade e termo de suavização ${ }^{1}$. Por fim, destaca-se também que todas as variáveis fiscais foram deflacionadas a preços de 2010 pelo índice Nacional de Preços ao Consumidor Amplo (IPCA). A seguir, é feita uma breve discussão da situação fiscal recente sobre as Unidades Federativas (UF) brasileiras e do levantamento dos dados.

\section{Finanças Públicas dos Estados Brasileiros}

O histórico de reestruturação das finanças públicas estaduais começa com a renegociação das dívidas em 1997. Tal fato é um marco para a história das finanças recentes dado o cenário pós-ajuste do Plano Real, uma vez que os estados necessitavam solucionar a insolvência financeira causada em parte pela enorme dívida contraída por governos anteriores ao ano de 1995. Nesse processo, buscaram-se alternativas que abordavam a renegociação da dívida e outras iniciativas para reduzir o tamanho do governo nos estados, entre elas: redução da folha de pagamentos e programas de demissão voluntária, privatização dos bancos estaduais e também adoção de um programa de ajuste fiscal de longo prazo (Piancastelli e Boueri, 2008).

Com o processo de ajuste fiscal e renegociação das dívidas, os estados conseguiram alcançar certa estabilidade nos indicadores fiscais, consequência inclusive de uma nova lei que parametrizava alguns indicadores de gastos e também zelava pelos indicadores de receitas e despesas locais. Essa lei foi nomeada Lei de Responsa-

\footnotetext{
${ }^{1}$ No Apêndice A. 1, são apresentados resultados nos quais a extração do componente cíclico é realizada por outro método, no caso o filtro BK (BAXTER; KING, 1995). Já no Apêndice A.2, são apresentados os resultados das estimativas com o parâmetro de suavização 100.
} 
bilidade Fiscal (LRF) ou Lei Complementar (LC) nº 101/2000 (Piancastelli e Boueri, 2008). ${ }^{2}$

Figura 1. Evolução da Média do Investimento Público/PIB dos Estados entre 1995 e 2016

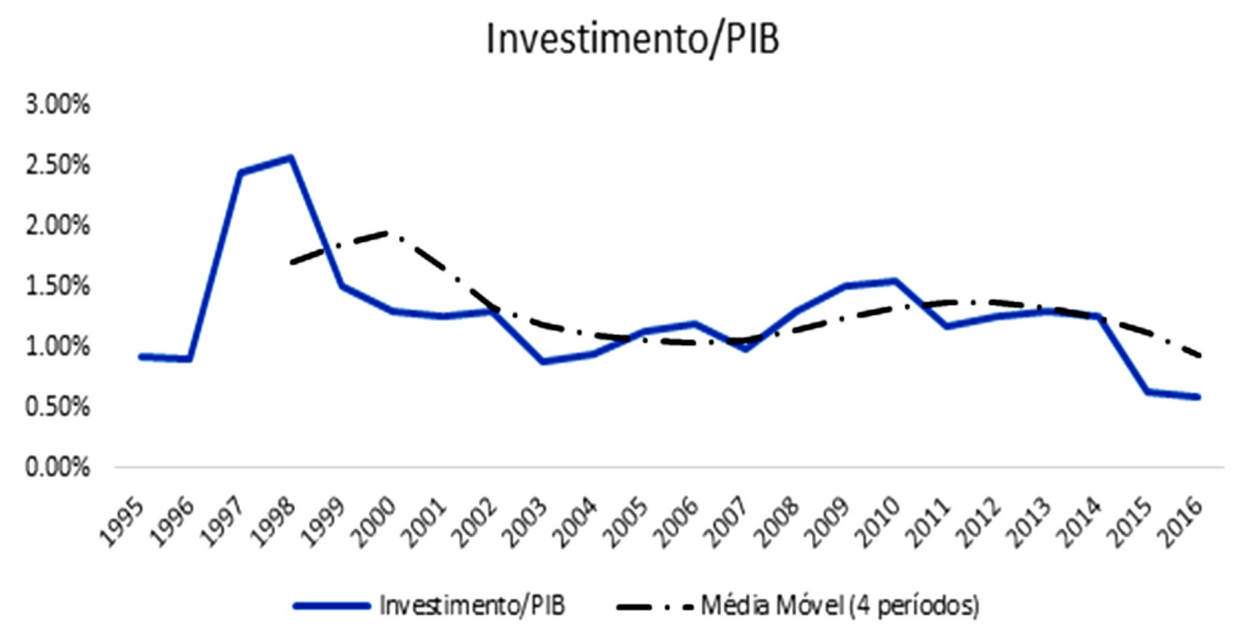

Fonte: Elaboração própria a partir de dados da Execução Orçamentária dos Estados.

Nos anos seguintes a 2013, as medidas de ajuste tomadas pelos estados para sanar o desarranjo das finanças recaiu quase inteiramente sobre o investimento público estadual. Tais medidas de contenção terminaram com a contração de novas dívidas, o que provocou mais contingenciamento futuro e aumentou a instabilidade do investimento público durante o período. Mais especificamente, vê-se uma queda drástica da trajetória do investimento dos governos locais como proporção do PIB entre os anos de 1997 e 2016 (Mendes, 2017). Conforme descrito na Figura 1, a proporção dos investimentos públicos no PIB dos estados apresenta queda até 2008 e, após uma pequena recuperação nos anos seguintes, volta a cair para o seu patamar mais baixo em 2016.

De fato, ao analisar a evolução das receitas e despesas das UF para o período 1995 até 2016, observam-se ao menos dois períodos distintos. Conforme descrito em Tinoco (2018), do lado da receita, vê-se uma nítida recuperação entre 1995 e 2006 , seguida de desaceleração econômica e, então, um retrocesso entre 2008 e 2016; já por parte da despesa, vê-se uma elevação persistente em todo o período, principalmente para a despesa com pessoal. Assim, o aumento das despesas não foi acompanhado pelo aumento equivalente das receitas e resultou em maior endividamento e menor capacidade de investimento público no longo prazo. Conforme analisado em Júnior e Aguiar (2018), esse problema se agravou no período de 2013 a 2015, provocando uma deterioração na situação fiscal das unidades federativas brasileiras.

\footnotetext{
${ }^{2}$ Por conta da vigência da LRF e de seus efeitos nos anos seguintes, foi realizado o teste de Chow de quebra estrutural para o ano de 2001 para cada estado. Os resultados estão no Apêndice A.4 e indicam que apenas 4 dos 27 estados analisados apresentam quebra estrutural no período analisado.
} 
Como consequência, observou-se uma propensão modesta de convergência do PIB per capita entre as regiões brasileiras durante o final dos anos 90 e início dos anos 2000. Já o período subsequente, sobretudo os anos após a adoção de políticas fiscais contracíclicas para combater a crise de 2008, é caracterizado por forte queda da atividade econômica nos estados (Mendes, 2017). Esse histórico recente aumenta o interesse em compreender os efeitos dos componentes do orçamento dos governos sobre a instabilidade da atividade econômica.

\subsection{Dados e Análise Descritiva das Variáveis}

Um aspecto importante dessa discussão está relacionado não só à trajetória das variáveis fiscais, como também às suas oscilações. Os dados utilizados para cálculo das médias e volatilidades foram coletados da Execução Orçamentária dos Estados disponibilizada na Secretaria do Tesouro Nacional e também do sistema SIDRA (Sistema de Recuperação Automática), disponibilizado pelo Instituto Brasileiro de Geografia e Estatística (IBGE).

Os dados disponíveis para todos os estados vão de 1997 até $2016 .{ }^{3}$ A Tabela 1 apresenta as principais estatísticas descritivas para as variáveis de atividade econômica (PIB), componentes fiscais e investimentos dos governos locais, além de suas respectivas volatilidades. Para a análise econométrica, os dados estão agrupados em períodos quadrienais (para o cálculo da volatilidade, vide discussão na Seção 3), gerando cinco unidades temporais (1997-2000; 2001-2004; 2005-2008;2009-2012; 2013-2016) para as 27 Unidades Federativas, totalizando 135 observações.

Como se pode notar na Tabela 1, as receitas totais no período estiveram em torno de $19 \%$ do PIB. Esse valor é muito semelhante à média das despesas no período. O crescimento do PIB estadual teve média de aproximadamente 5\% para o período de análise, porém apresentou uma grande dispersão entre 1997 e 2016, com máxima de $23 \%$ e mínima de $-16 \%$ de crescimento. Por outro lado, o investimento público como proporção do PIB tem média de 2,24\% para todo o período usado como amostra, além de desvio-padrão de 0,021. É uma média muito baixa quando comparada com a média das despesas e receitas no período. O PIB per capita inicial (medido em logaritmo natural) apresenta uma média para a amostra de 9,4 e seu desvio-padrão é de 0,54. Essa variável indica se, condicional ao PIB inicial, as economias locais estão se aproximando ou se afastando entre si, de modo que se espera um coeficiente positivo (negativo) se as economias estiverem em trajetória divergente (convergente).

\footnotetext{
${ }^{3}$ Existem dados disponiveis para periodos anteriores, mas não para todo o conjunto de variáveis em todos os estados.
} 
Tabela 1. Estatísticas descritivas

\begin{tabular}{lccccc}
\hline \hline Variável & Média & Mínimo & Máximo & Desvio-Padrão & $\mathrm{N}$ \\
\hline PIB per Capita Inicial & 9.409 & 8.249 & 10.98 & 0.5484 & 135 \\
Crescimento do PIB Estadual & 0.052 & $-0,02$ & 0.134 & 0.024 & 135 \\
Investimento (\% do PIB) & 0.0224 & 0.004 & 0.121 & 0.0221 & 135 \\
Receita Total (\% do PIB) & 0.1926 & 0.086 & 0.494 & 0.0842 & 135 \\
Despesa Total (\% do PIB) & 0.1859 & 0.085 & 0.445 & 0.073 & 135 \\
Dívida Total (\% do PIB) & 0.148 & 0.016 & 0.404 & 0.092 & 135 \\
Volatilidade PIB (Filtro HP) & 0.032 & 0.005 & 0.116 & 0.018 & 135 \\
Volatilidade Investimento (Filtro HP) & 0.006 & 0.001 & 0.037 & 0.006 & 135 \\
Volatilidade Receita Total (Filtro HP) & 0.013 & 0.001 & 0.126 & 0.014 & 135 \\
Volatilidade Despesa Total (Filtro HP) & 0.011 & 0.001 & 0.0522 & 0.009 & 135 \\
Volatilidade Dívida Total (Filtro HP) & 0.012 & 0.001 & 0.097 & 0.013 & 135 \\
Crescimento Populacional & 0.0179 & $-0,0858$ & 0.075 & 0.012 & 135 \\
Capital Humano & 6.283 & 3.477 & 9.991 & 1.290 & 135 \\
\hline \hline
\end{tabular}

Fonte: Elaborado pelos autores a partir de dados da Execução Orçamentária dos Estados.

As medidas de volatilidade também são consideradas como proporção do PIB. As volatilidades das variáveis fiscais (receitas, despesas e dívida) são muito semelhantes e apresentam um valor médio que corresponde à metade da volatilidade do PIB. Observa-se também que a volatilidade média do investimento público estadual é muito menor do que a volatilidade da atividade econômica local no período analisado, sendo de 0,006 contra 0,032 , respectivamente.

A Tabela 2 apresenta a correlação das variáveis estaduais de volatilidades fiscais, de crescimento e de investimento público. É interessante notar a elevada correlação entre a variável despesa e investimento, de 0,65, maior que a própria correlação entre receita e despesa, de 0,42. Além disso, as volatilidades da receita e do investimento público também apresentam uma elevada correlação positiva. As informações da Tabela 2 indicam que é preciso ficar atento à questão de multicolinearidade dessas variáveis na aplicação do modelo econométrico. Por conta disso, a maior parte das especificações na Seção 5 vai evitar que essas variáveis fiscais sejam utilizadas simultaneamente como variáveis independentes.

Adicionalmente, para ilustrar as associações entre tamanho da economia e atividade econômica, a Figura 2 apresenta a correlação entre a variável de volatilidade do crescimento, medida como desvio padrão do componente cíclico, e o PIB per capita dos estados. Existe uma associação negativa entre essas duas variáveis, ou seja, estados com maior tamanho econômico tendem a apresentar uma menor volatilidade no PIB, 
apesar de a magnitude dessa correlação não ser muito forte $(-0,093)$.

Tabela 2. Correlação entre as Volatilidades

\begin{tabular}{lccccc}
\hline \hline & $\begin{array}{c}\text { Volatilidade } \\
\text { PIB }\end{array}$ & $\begin{array}{c}\text { Volatilidade } \\
\text { Investimento }\end{array}$ & $\begin{array}{c}\text { Volatilidade } \\
\text { Receita Total }\end{array}$ & $\begin{array}{c}\text { Volatilidade } \\
\text { Despesa } \\
\text { Total }\end{array}$ & $\begin{array}{c}\text { Volatilidade } \\
\text { Dívida Total }\end{array}$ \\
\hline Volatilidade PIB & 1 & $-0,082$ & $-0,049$ & $-0,061$ & $-0,009$ \\
Volatilidade Investimento & & 1 & 0,427 & 0,640 & 0,325 \\
Volatilidade Receita Total & & & 1 & 0,393 & 0,220 \\
Volatilidade Despesa Total & & & 1 & 0,472 \\
Volatilidade Divida Total & & & & 1 \\
\hline \hline
\end{tabular}

Fonte: Elaborado pelos autores.

Figura 2. Volatilidade do PIB e Tamanho da UF

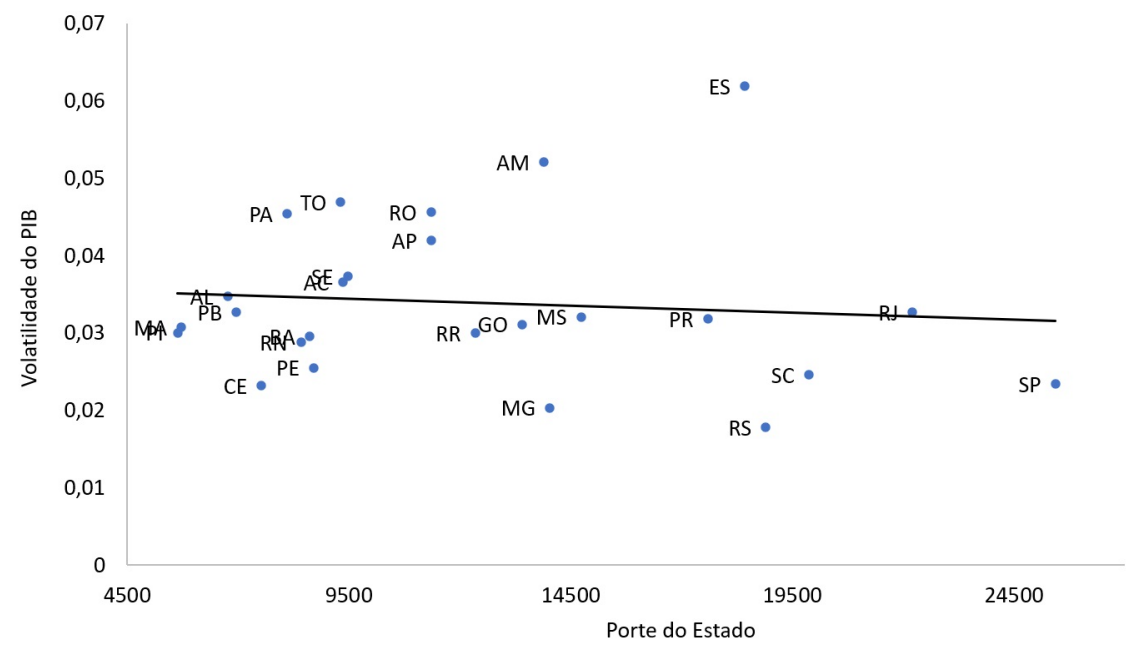

Fonte: elaboração própria a partir de dados da Execução Orçamentária dos Estados

De maneira complementar, as Figuras 3 e 4 apresentam a distribuição do crescimento médio e da volatilidade média do PIB, respectivamente, por grupos de unidades federativas para o período de 1997 a 2016. Nessas figuras, os estados são ordenados de acordo com seu PIB per capita e são reunidos em dois grupos: os treze com maior e os treze com menor renda per capita (o DF é excluído da amostra do gráfico).

A análise da Figura 3 sugere que nesse período os estados classificados como menores apresentam maior crescimento da atividade econômica, com média próxima de $5 \%$, em comparação com uma média aproximada de $3,5 \%$ para os estados maiores. A distribuição da média de crescimentos dos estados menores é mais próxima de uma distribuição normal, enquanto a distribuição do crescimento médio dos estados maiores apresenta uma assimetria positiva, com os valores das médias se concentrando na extremidade inferior da escala. 
Figura 3. Distribuição da Média do Crescimento de acordo com o tamanho da UF

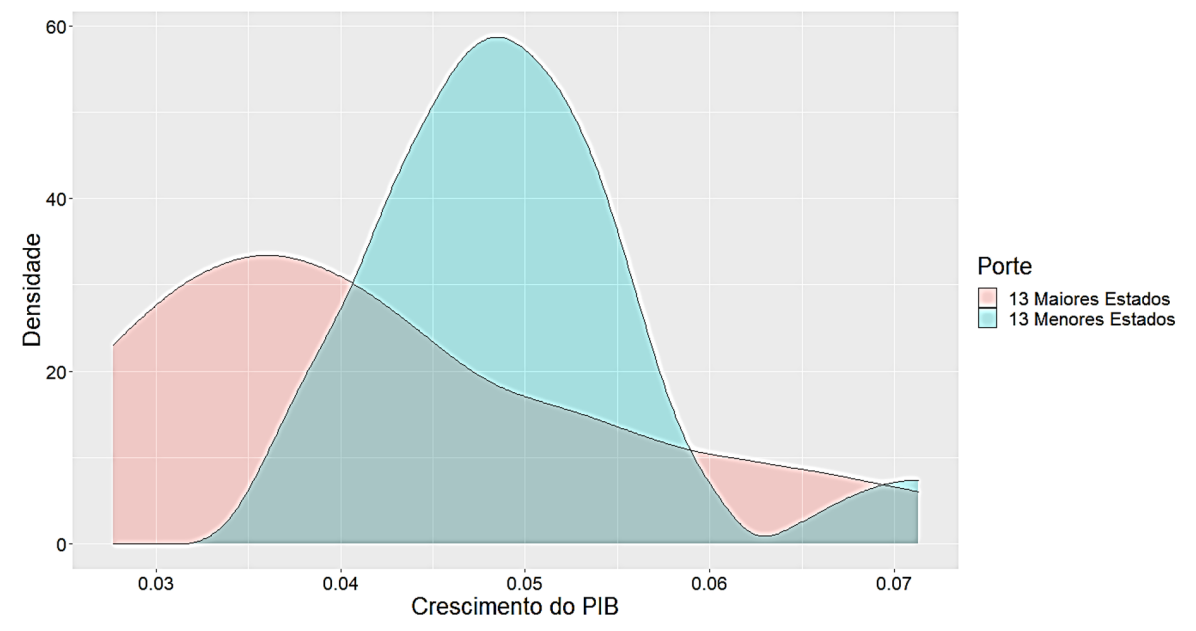

Fonte: Elaboração própria a partir de dados da Execução Orçamentária dos Estados

A Figura 4 apresenta a distribuição da volatilidade do crescimento econômico com os estados divididos novamente em dois grupos de acordo com o PIB per capita.

Figura 4. Distribuição da Volatilidade Média do Crescimento por tamanho da UF

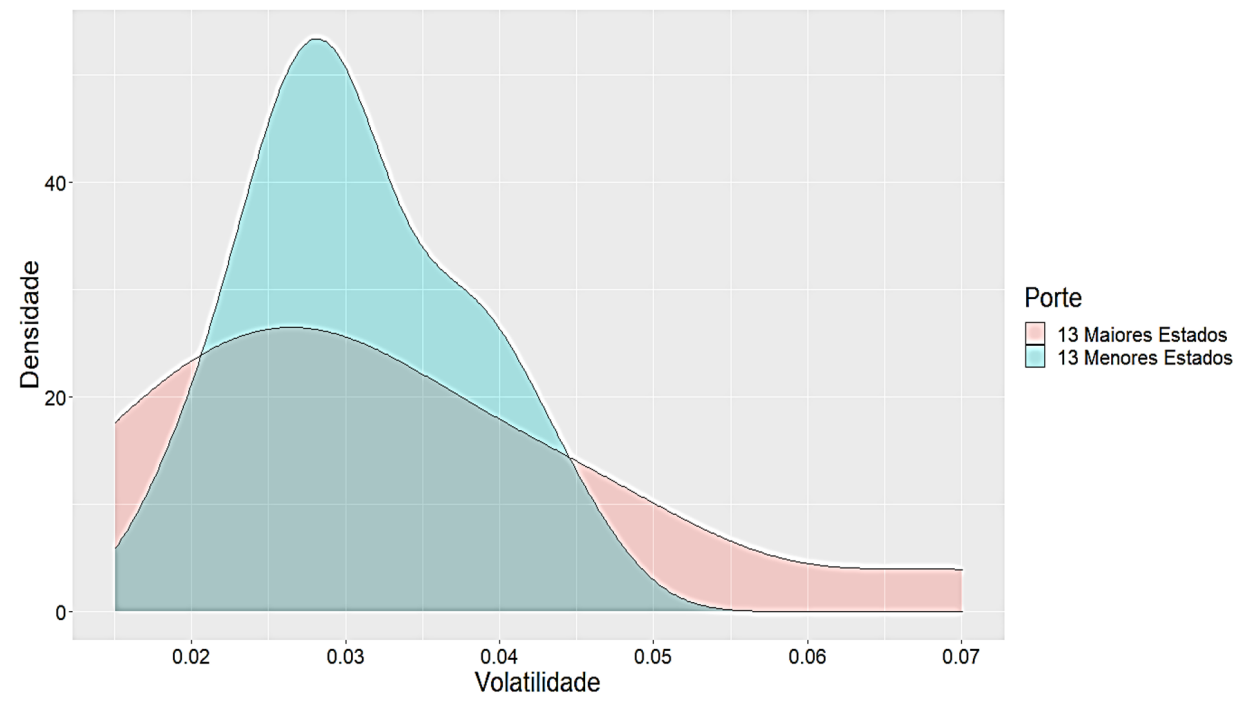

Fonte: Elaboração própria a partir de dados da Execução Orçamentária dos Estados

As curvas de densidade da Figura 4 sugerem que os estados menores apresentam uma distribuição mais concentrada da volatilidade da atividade econômica quando comparados com os estados maiores, cujo padrão de volatilidade é mais disperso.

Essas relações entre volatilidade da política fiscal, crescimento da atividade econômica e investimentos públicos estaduais são abordadas de uma maneira mais sistemática na próxima seção, a partir da aplicação do modelo econométrico para as unidades da federação no Brasil. 


\section{Resultados}

Nesta seção, são apresentados os principais resultados das estimativas referentes aos efeitos da volatilidade da atividade econômica e da política fiscal sobre o crescimento.

A Tabela 3 apresenta os resultados para a especificação descrita na função (1) para as Unidades Federativas. Além do uso da volatilidade do PIB sobre o crescimento como covariada, são utilizadas as variáveis de controle sugeridas em Ramey e Ramey (1994), Afonso e Furceri (2010) e Furceri (2010): logaritmo do PIB per capita inicial do período, proporção do investimento público em relação ao PIB, capital humano (medido como os anos médios de escolaridade dos habitantes) e crescimento populacional (vide discussão Guadro 1).

É importante lembrar que a especificação base usa o filtro HP (com parâmetro de suavização 6,25, vide seção 3 para detalhamento) para obter o componente cíclico da série (PIB, investimento público ou receitas e despesas). Após a eliminação do termo de tendência, é utilizado o desvio padrão de um intervalo de quatro anos da série para construir a variável de volatilidade, de modo que o período de análise (1997 a 2016) é formado por cinco observações temporais. As variáveis de controle, com exceção do PIB inicial, seguem a média desses intervalos quadrienais.

Todos os resultados na Tabela 3 consideram a especificação em dados de painel com efeito fixo de tempo e localidade. A diferença entre as especificações é a inclusão ou não das variáveis de volatilidades de investimentos públicos (colunas I e II) e de crescimento do PIB nas regressões com as variáveis fiscais (colunas III a VI) para verificar se a existência de relações lineares entre as variáveis explicativas afeta as estimativas.

Os resultados apresentados na coluna II da Tabela 3 sugerem que a volatilidade da atividade econômica apresenta um efeito negativo sobre a taxa de crescimento, porém não significativo. O coeficiente estimado sugere que um aumento de 0,01 no desviopadrão da medida de volatilidade entre os estados provoca uma redução de 0,002 1 ponto percentual na taxa de crescimento de longo prazo. De maneira similar, pode-se dizer que um aumento de um ponto percentual no desvio-padrão da volatilidade gera em média um efeito negativo de $0,0067\left(0,21^{*} 0,032\right)$ ponto percentual no crescimento dos estados. ${ }^{4}$

\footnotetext{
${ }^{4} \mathrm{O}$ efeito sobre o crescimento é obtido pela multiplicação entre o coeficiente estimado para a volatilidade com o valor médio da variável de volatilidade em questão (vide Afonso e Furceri (2010); seção 4.2, nota de rodapé 24$)$.
} 


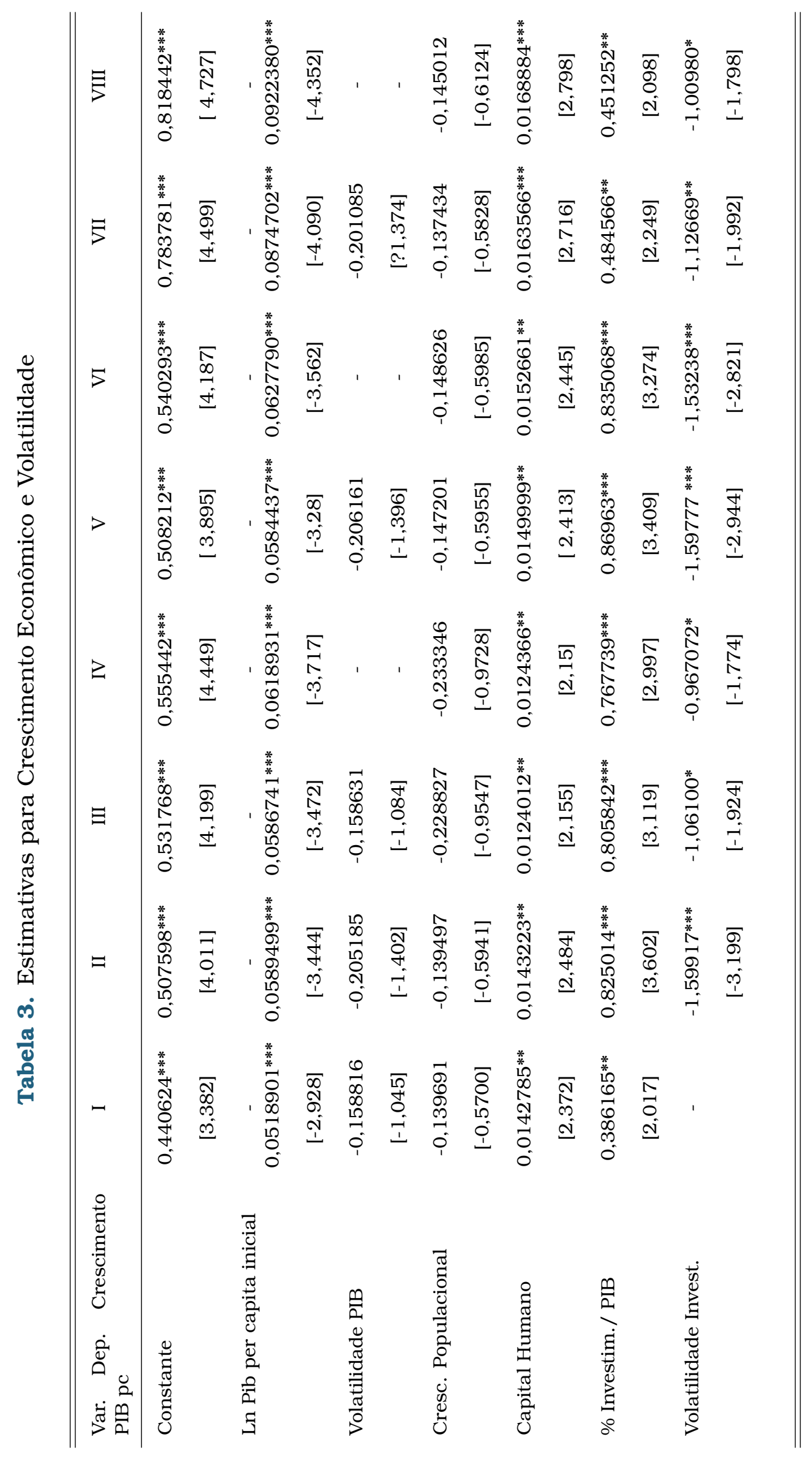




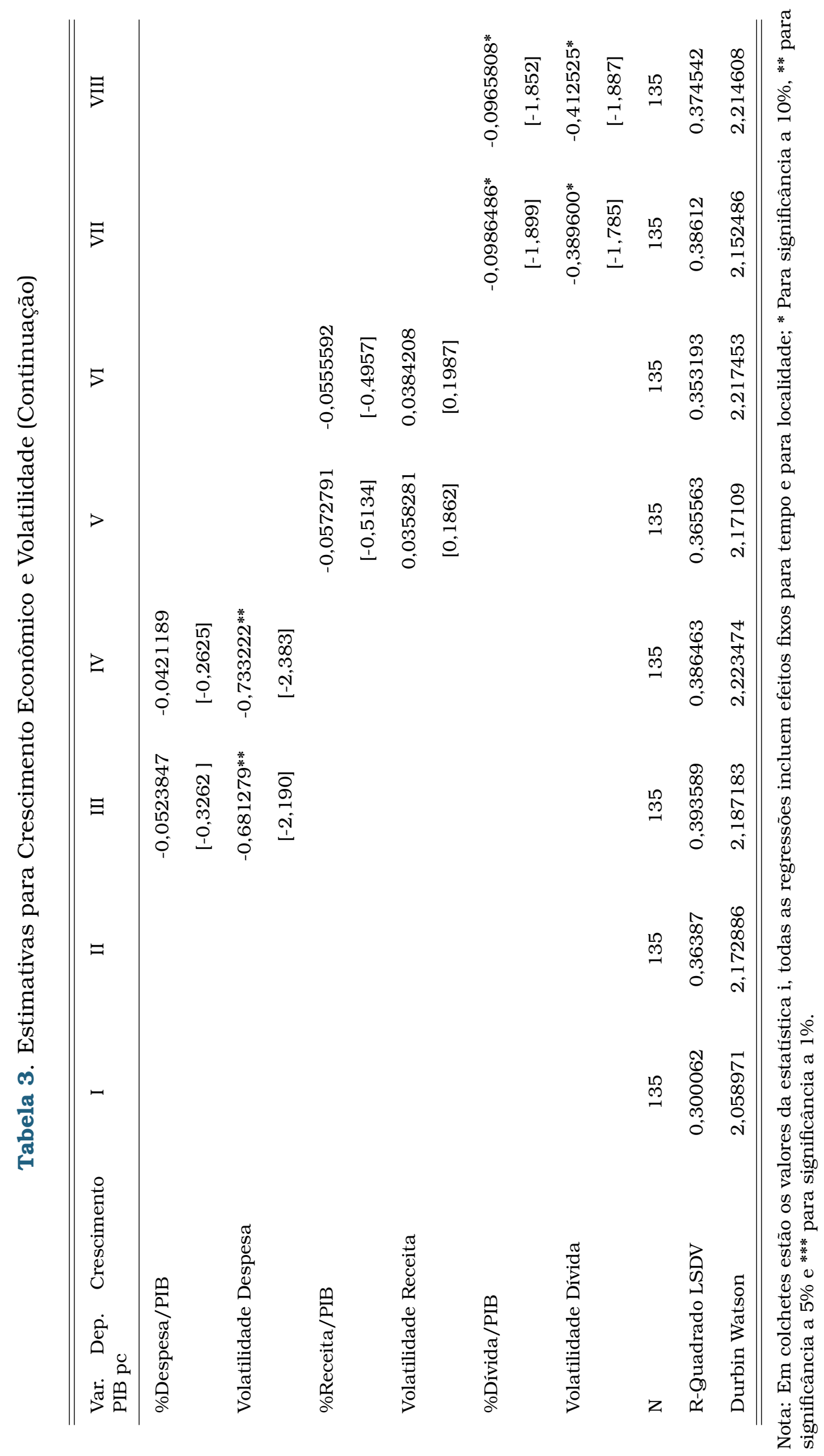


Já a variável referente à proporção do investimento público estadual sobre o PIB apresenta um efeito muito maior e significativo na taxa de crescimento. De fato, o coeficiente estimado para essa variável na coluna II sugere que o aumento de um ponto percentual na parcela de investimento público de longo prazo gera um impacto positivo de aproximadamente 0,82 ponto percentual na taxa de crescimento. Vale notar que esse efeito é significativo no nível de 1\%. Já o aumento da volatilidade do investimento público gera um impacto negativo e estatisticamente significativo no crescimento, com um coeficiente estimado de aproximadamente 1,6. Comparando-se os efeitos das volatilidades de investimento e PIB, pode-se afirmar que o efeito negativo da oscilação do investimento público local $\left(0,006^{*} 1,6=0,01\right)$ sobre o crescimento é quase duas vezes maior do que o efeito estimado para a volatilidade do próprio PIB.

Em relação às demais variáveis explicativas, nota-se que o crescimento populacional está negativamente associado ao crescimento da atividade econômica, apesar de o coeficiente não ser estatisticamente significativo. Conforme esperado, o aumento do capital humano (aumento dos anos de escolaridade) gera um impacto positivo e significativo (nas especificações em painel, colunas III e IV) no crescimento das localidades. Por fim, o coeficiente do PIB inicial é negativo, o que indica que, uma vez controlado o nível da atividade econômica no início do período, a diferença na taxa de crescimento entre as localidades diminui. Em termos qualitativos, os resultados dos coeficientes das variáveis de controle são semelhantes aos encontrados por Furceri (2010) para países desenvolvidos.

Os resultados das colunas III a VI referem-se às estimativas das especificações que seguem as anteriores, porém acrescidas das variáveis fiscais de despesas, receitas e dívida dos governos. Assim como sugerido por Afonso e Furceri (2010), a ideia é explorar o efeito do tamanho de governo (medido como despesas ou receitas públicas) e suas volatilidades sobre a taxa de crescimento. Conforme esperado, o tamanho do governo, seja medido na forma de gastos públicos ou receitas totais, apresenta uma associação negativa ao crescimento econômico. Os resultados nas colunas I e III sugerem que o aumento de um ponto percentual das despesas (receitas) públicas provoca um decréscimo de $0,05(0,06)$ ponto percentual no crescimento. Vistos de outra forma, esses resultados sugerem que estados com maior participação do governo como proporção do PIB crescem mais devagar. Por outro lado, é importante notar que nenhum dos coeficientes é estatisticamente significativo, e que ambos apresentam uma magnitude bem menor do que a do coeficiente estimado para o investimento público local.

Já os resultados obtidos para a volatilidade das despesas (coluna III) e das receitas (coluna V) sugerem que oscilações nas receitas são menos importantes para compreender o crescimento dos estados no período. O coeficiente estimado para a volatilidade das receitas é insignificante e próximo de zero. Por sua vez, o coeficiente estimado para a volatilidade das despesas sugere que o aumento de um ponto percentual no desvio-padrão da volatilidade da despesa provoca uma queda de 0,007 
$(0,68 * 0,01)$ no crescimento. Esse efeito é significativo e apresenta, nessa especificação, um impacto semelhante ao estimado para investimento $(0,006 * 1,06)$ na atividade econômica, apesar da maior participação do componente da despesa no PIB.

Ainda em relação às variáveis fiscais, o nível da dívida e a volatilidade da dívida se mostram importantes para compreender o crescimento econômico. De acordo com os resultados na coluna VII, o aumento de um ponto percentual na parcela da dívida em relação ao PIB provoca uma queda de aproximadamente 0,10 ponto percentual na taxa de crescimento. Isso indica que localidades onde a proporção da dívida em relação ao PIB vem aumentando tendem a crescer menos no longo prazo. Além disso, a maior oscilação do estoque da dívida no decorrer do tempo também apresenta um efeito negativo e significativo sobre a atividade econômica. Os resultados apresentados nas colunas VII e VIII sugerem que o aumento de um ponto percentual no desvio-padrão da volatilidade da dívida causa um decréscimo de 0,005 $(0,39 * 0,012)$ na taxa de crescimento. Esse efeito é semelhante ao encontrado para oscilação no investimento público estadual.

É interessante notar que em nenhuma das estimativas na Tabela 3 a variável volatilidade do PIB é estatisticamente significativa. Por outro lado, o coeficiente estimado para a volatilidade de investimento público estadual (entre -0,97 e -1,60, colunas IV e II, respectivamente) é estatisticamente significativo em todas as especificações. $O$ efeito estimado para a volatilidade do investimento público, apesar de significativo, é menor quando a variável de volatilidade da despesa é incluída na especificação. Essa queda no coeficiente de volatilidade do investimento público local deve estar associada à correlação com a variável de despesa (vide Tabela 2). Em relação às demais variáveis de controle, pode-se dizer que os coeficientes estimados para o PIB inicial e capital humano mantêm-se relativamente estáveis, com efeitos negativos e positivos respectivamente.

Por fim, em relação aos testes estatísticos, o valor próximo a dois em todas as estimativas para o teste de Durbin-Watson indica ausência de autocorrelação de primeira ordem nos termos de erro. Já o valor do teste R quadrado entre 0,36 e 0,39, observado nas estimativas da Tabela 3, é um pouco superior ao encontrado por Afonso e Jalles (2012) para uma especificação também de painel com efeitos fixos e sugere um bom ajuste do modelo.

A seguir, a subseção 5.1 complementa a discussão dessa seção, explorando as relações entre volatilidade e crescimento a partir da divisão de dois subgrupos da amostra de acordo com o tamanho do PIB per capita, conforme retratado nas Figuras 3 e 4.

\subsection{Análise da Volatilidade de Acordo com o Tamanho dos Estados}

Um desdobramento natural dessa discussão é verificar se os resultados são diferentes de acordo com o tamanho da economia dessas localidades. Segundo Furceri e 
Ribeiro (2008), o efeito da volatilidade pode ser diferente de acordo com o tamanho da economia local. Dessa forma, a Tabela 4 apresenta as mesmas estimativas da Tabela 3 , porém para a amostra dividida em dois grupos de acordo com o PIB per capita: em uma subamostra estão os treze maiores estados e na outra os treze menores. A ideia é verificar se os resultados indicados na Tabela 3 mudam de acordo com o tamanho das localidades. Assim, as colunas I a III na Tabela 4 apresentam os resultados estimados para os maiores estados em termos de PIB per capita, enquanto os as colunas IV a VI demonstram os mesmos resultados para o grupo dos estados classificados como menores. Os efeitos da volatilidade de investimento público e das variáveis fiscais são bastante diferentes entre os grupos.

Os resultados da Tabela 4 indicam que para o grupo dos maiores estados o efeito negativo do aumento da volatilidade do investimento público é muito maior em comparação com a amostra total. Na coluna II, o coeficiente estimado indica que um aumento de um ponto percentual no desvio-padrão da volatilidade do investimento gera em média um efeito negativo de $0,018\left(3,04^{*} 0,006\right)$ ponto percentual no crescimento de longo prazo nesse grupo. De maneira similar, o aumento de um ponto percentual na proporção de investimento público em relação ao PIB gera um impacto positivo de aproximadamente 1,59 pontos percentuais na taxa de crescimento.

Ademais, os resultados referentes aos efeitos das variáveis fiscais para os estados com PIB maior, tanto em termos de receitas como de despesas (colunas I e II na Tabela 4), e de suas respectivas volatilidades, são todos não significativos. O mesmo ocorre em relação à variável da proporção da dívida/PIB. Em conjunto, esses resultados sugerem que para os estados com maior PIB per capita, o comportamento da variável investimento público (tanto em termos de parcela do PIB como de sua volatilidade) é mais importante para descrever a trajetória do crescimento econômico do que o desempenho das variáveis fiscais.

Em contraposição a esse resultado, as estimativas nas colunas IV e VI sugerem que oscilações nas variáveis fiscais são mais importantes para compreender o crescimento de longo prazo para o grupo de estados com menor PIB per capita. Os resultados da coluna IV sugerem que o acréscimo de um ponto percentual no desvio-padrão da volatilidade da despesa provoca em média um decréscimo de $0,01\left(0,87^{*} 0,012\right)$ ponto percentual no crescimento de longo prazo dessas localidades. Um impacto menor é encontrado para a volatilidade da receita $(0,007)$. O coeficiente estimado para essas duas volatilidades é estatisticamente significativo, assim como o coeficiente da volatilidade da proporção da dívida sobre o PIB, cujo efeito estimado sobre o crescimento de longo prazo apresenta uma magnitude mais próxima ao efeito da volatilidade da despesa (0,009). 


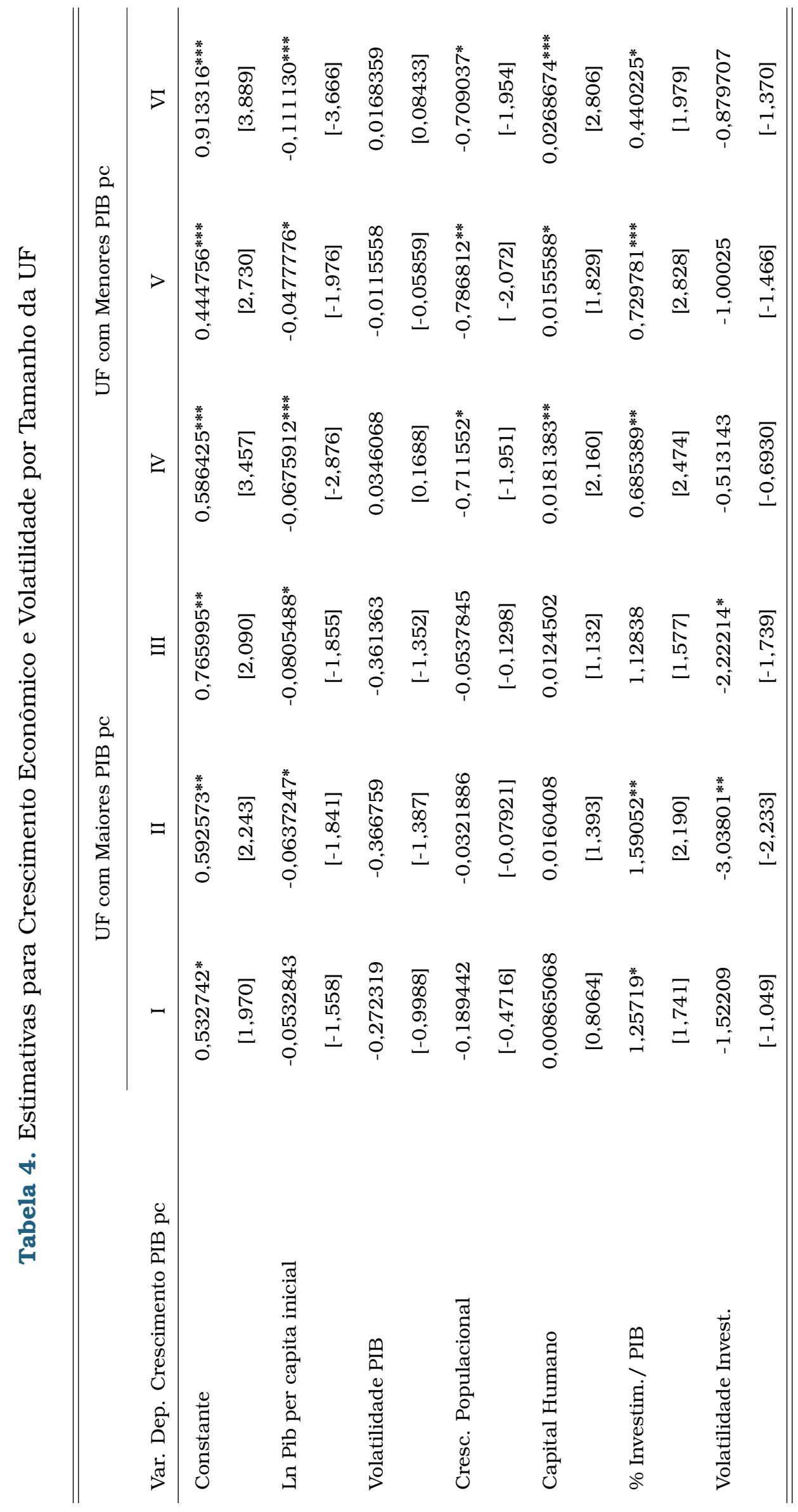




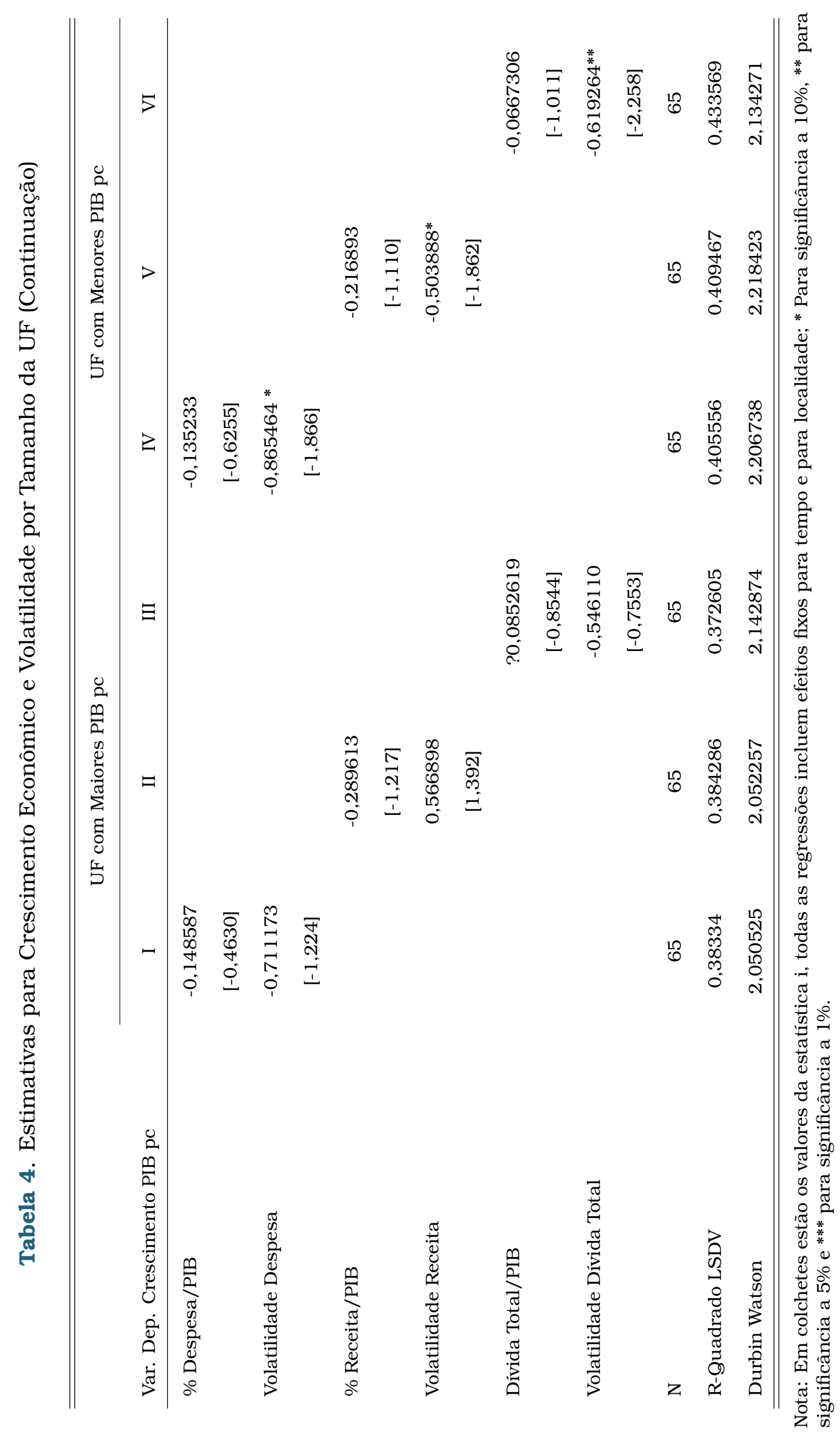


Importante notar que para esse grupo de estados com menor PIB per capita, a variável referente à parcela de investimento público como proporção do PIB continua significativa, com coeficiente estimado entre 0,44 e 0,73 (colunas V e VI). Por outro lado, apesar dos resultados nas colunas IV a VI indicarem uma associação negativa entre a volatilidade do investimento público e o crescimento do PIB, as estimativas apresentam uma magnitude menor quando comparadas com as estimativas dos estados de maior volume econômico e não são estatisticamente significativas.

Desse modo, os resultados em conjunto das Tabelas 3 e 4 sugerem que o percentual de investimento público estadual em relação ao PIB é uma variável importante cujo aumento gera efeitos positivos para todos os estados. Já em relação a volatilidade, o investimento público se mostrou mais relevante para descrever a trajetória de crescimento nos estados com maior PIB per capita. Por sua vez, as variáveis referentes à volatilidade fiscal (despesas, receitas e tamanho da dívida) se mostram significativas para explicar a trajetória de crescimento econômico dos estados com menor PIB per capita. Esse resultado é importante, pois sugere que oscilações inesperadas da política fiscal produzem um efeito negativo maior sobre o crescimento econômico dos estados com menor atividade econômica. Já para os estados com maior PIB per capita, a menor oscilação do investimento público tende a produzir um impacto maior na taxa de crescimento do PIB de longo prazo. Em nenhuma dessas estimativas, o componente cíclico do PIB se mostrou relevante.

\section{Conclusão}

Literatura anterior sobre crescimento econômico destaca os efeitos negativos da volatilidade sobre os ciclos da economia (Ramey e Ramey, 1994). Esse trabalho explora essa literatura que investiga os efeitos das oscilações econômicas sobre o PIB e incorpora a discussão trazida por Afonso e Furceri (2010) a respeito do papel desempenhado pelas variáveis fiscais de despesa, receita e tamanho da dívida nesse processo.

Uma novidade neste trabalho é que além dos efeitos sobre a amostra total, este artigo investiga os efeitos da instabilidade das variáveis fiscais e do investimento público sobre o crescimento considerando o tamanho das economias locais. Em particular, são investigados os efeitos das variáveis fiscais e suas volatilidades sobre as unidades federativas do Brasil para o período de 1997 a 2016.

Os resultados sugerem que o investimento público e a dívida como proporção do PIB são dois fatores importantes para compreender a trajetória de crescimento de longo prazo dos estados. Enquanto o aumento de um ponto percentual na primeira variável apresenta um efeito positivo e significante entre 0,48 e 0,87 sobre o crescimento, o aumento de um ponto percentual da dívida como proporção do PIB provoca um efeito negativo e significante de aproximadamente 0,10 na taxa de crescimento de longo prazo. Adicionalmente, um aumento de volatilidade nessas duas variáveis 
apresenta um efeito negativo sobre a atividade econômica. Porém, os resultados sugerem que o aumento de um ponto percentual no desvio padrão da volatilidade do investimento público apresenta um efeito sobre o crescimento do PIB (de 0,01) que é aproximadamente duas vezes maior que o impacto previsto para um aumento da volatilidade da dívida na mesma proporção.

Em relação à variável do tamanho de governo, seja medido como parcela de despesa, seja receita como proporção do PIB, um aumento apresenta uma associação negativa ao crescimento econômico. Os resultados indicam que o aumento de um ponto percentual das despesas (receitas) públicas provoca um decréscimo de 0,05 $(0,06)$ pontos percentuais no crescimento de longo prazo. As outras variáveis fiscais relativas a despesas e receitas dos estados se mostram menos importantes para compreender o crescimento econômico.

Por fim, os resultados por subamostras de estados segundo PIB per capita sugerem que para o grupo dos estados com maior tamanho as variáveis associadas a investimentos públicos (tanto como proporção do PIB como em termos de volatilidade) são as que mais afetam a trajetória de crescimento econômico. Em contraposição, para o grupo de estados com menor porte, aumentos na volatilidade das variáveis fiscais de receitas, despesas e dívida são mais importantes para compreender a diminuição do crescimento econômico dessas localidades. Esses resultados sugerem que uma menor oscilação no comportamento das receitas são um componente importante na recuperação de capacidade de investimento público das localidades menores.

Enquanto a associação positiva entre investimento público e crescimento no Brasil já foi discutida em pesquisa anterior (Rocha e Giuberti, 2007), este artigo apresenta novas evidências a respeito do efeito de políticas fiscais mais estáveis, sobretudo em relação às receitas próprias, sobre o crescimento econômico dos estados. Dentro desse tópico, pesquisas futuras sobre as relações entre investimento público e privado no âmbito local podem ajudar a compreender a trajetória do crescimento econômico dos estados no Brasil.

\section{Referências}

Afonso, A. e Furceri, D. (2010). Government size, composition, volatility and economic growth. European Journal of Political Economy, 26(4):517-532.

Afonso, A. e Jalles, J. T. (2012). Fiscal volatility, financial crises and growth. Applied Economics Letters, 19(18):1821-1826.

Aghion, P., Hemous, D., e Kharroubi, E. (2009). Credit constraints, cyclical fiscal policy and industry growth. Texto para discussão, National Bureau of Economic Research.

Al-Marhubi, F. (1998). Cross-country evidence on the link between inflation volatility and growth. Applied Economics, 30(10):1317-1326. 
Alesina, A. e Wacziarg, R. (1998). Openness, country size and government. Journal of public Economics, 69(3):305-321.

Alt, J. E. e Lowry, R. C. (1994). Divided government, fiscal institutions, and budget deficits: Evidence from the states. American Political Science Review, Página 811828.

Fatás, A. e Mihov, I. (2006). The macroeconomic effects of fiscal rules in the us states. Journal of public economics, 90(1-2):101-117.

Frankel, J. e Rose, A. (2002). An estimate of the effect of common currencies on trade and income. The quarterly journal of economics, 117(2):437-466.

Furceri, D. (2007). Is government expenditure volatility harmful for growth? a crosscountry analysis. Fiscal Studies, 28(1):103-120.

Furceri, D. (2010). Long-run growth and volatility: which source really matters? Applied Economics, 42(15):1865-1874.

Furceri, D. e Ribeiro, M. P. (2008). Government spending volatility and the size of nations.

Júnior, J. L. R. e Aguiar, F. (2018). Understanding the evolution of the fiscal situation of the brazilian states; 2006-2015. EconomiA, 19(1):105-131.

Lucas, R. (1987). Models of Bussiness Cycles.

Mendes, C. C. (2017). Evolução fiscal e financeira dos estados brasileiros (2012-2015): desafios conjunturais e restrições estruturais.

Piancastelli, M. e Boueri, R. (2008). Dívida dos estados 10 anos depois. Texto para discussão, Texto para Discussão.

Pindyck, R. S. (1990). Irreversibility, uncertainty, and investment. Texto para discussão, National Bureau of Economic Research.

Pindyck, R. S. e Solimano, A. (1993). Economic instability and aggregate investment. NBER macroeconomics annual, 8:259-303.

Poterba, J. M. (1994). State responses to fiscal crises: The effects of budgetary institutions and politics. Journal of political Economy, 102(4):799-821.

Ramey, G. e Ramey, V. A. (1994). Cross-country evidence on the link between volatility and growth. Texto para discussão, National bureau of economic research.

Rocha, F. e Giuberti, A. C. (2007). Composição do gasto público e crescimento econômico: uma avaliação macroeconômica da qualidade dos gastos dos estados brasileiros. Economia Aplicada, 11(4):463-485.

Sarel, M. (1996). Nonlinear effects of inflation on economic growth. Staff Papers, 43(1):199-215. 
Tinoco, G. (2018). The fiscal sustainability of brazilian states: current situation and perspective ahead. Revista do BNDES, 25(50):299-344.

Este artigo está licenciado com uma CC BY 4.0 license. 


\section{Appendix}

Tabela A1. Estimativas para Crescimento e Volatilidade (volatilidades com filtro BK)

\begin{tabular}{|c|c|c|c|}
\hline Var. Dep. Crescimento PIB pc & I & II & III \\
\hline \multirow[t]{2}{*}{ Ln Pib per capita inicial } & $-0,0232672 * *$ & $-0,0243207^{* *}$ & $-0,0869901^{* * *}$ \\
\hline & {$[-2,280]$} & {$[-2,328]$} & {$[-4,118]$} \\
\hline \multirow[t]{2}{*}{ Volatilidade PIB } & 0.0205274 & $-0,0224353$ & $-0,216966$ \\
\hline & {$[0,1502]$} & {$[-0,1636]$} & {$[-1,302]$} \\
\hline \multirow[t]{2}{*}{ Cresc. Populacional } & $-0,140816$ & $-0,0982600$ & $-0,135685$ \\
\hline & {$[-0,7955]$} & {$[-0,5443]$} & {$[-0,5750]$} \\
\hline \multirow[t]{2}{*}{ Capital Humano } & 0.00527811 & 0.00681025 & $0,0163414^{* * *}$ \\
\hline & {$[1,301]$} & {$[1,590]$} & {$[2,711]$} \\
\hline \multirow[t]{2}{*}{ \% Investim./ PIB } & $0,590609 * * *$ & $0,659929 * * *$ & $0,538757^{* *}$ \\
\hline & {$[3,302]$} & {$[3,608]$} & {$[2,513]$} \\
\hline \multirow[t]{2}{*}{ Volatilidade Invest. } & $-0,358807$ & $-1,10637 * *$ & $-1,19719^{* *}$ \\
\hline & {$[-0,6152]$} & {$[-2,174]$} & {$[-2,202]$} \\
\hline \multirow[t]{2}{*}{ \% Despesa/PIB } & $-0,0647795$ & & \\
\hline & {$[-1,285]$} & & \\
\hline \multirow[t]{2}{*}{ Volatilidade Despesa } & $-0,659237^{* *}$ & & \\
\hline & {$[-2,172]$} & & \\
\hline \multirow[t]{2}{*}{ \% Receita/PIB } & & $-0,0714396$ & \\
\hline & & {$[-1,562]$} & \\
\hline \multirow[t]{2}{*}{ Volatilidade Receita } & & 0.0210318 & \\
\hline & & {$[0,1322]$} & \\
\hline \multirow[t]{2}{*}{ Dívida Total/PIB } & & & $-0,0947238^{*}$ \\
\hline & & & {$[-1,821]$} \\
\hline \multirow[t]{2}{*}{ Volatilidade Dívida Total } & & & $-0,406570^{*}$ \\
\hline & & & {$[-1,780]$} \\
\hline $\mathrm{N}$ & 135 & 135 & 135 \\
\hline R-Quadrado LSDV & 0.231482 & 0.208875 & 0.384987 \\
\hline Durbin Watson & 2.235 .989 & 2.211 .231 & 2.155 .638 \\
\hline
\end{tabular}

Nota: Notas: Em colchetes estão os valores da estatística t; todas as regressões incluem efeitos fixos para tempo e para localidade; * para significância a $10 \%,{ }^{* *}$ para significância a $5 \%$ e *** para significância a $1 \%$. 
Tabela A2. Estimativas para Crescimento e Volatilidade (Lambda 100 no filtro HP)

\begin{tabular}{|c|c|c|c|}
\hline Var. Dep. Crescimento PIB pc & I & III & V \\
\hline \multirow[t]{2}{*}{ Constante } & $0,475683^{* * *}$ & $0,443945^{* * *}$ & $0,748184^{* * *}$ \\
\hline & {$[3,741]$} & {$[3,449]$} & {$[4,405]$} \\
\hline \multirow[t]{2}{*}{ Ln Pib per capita inicial } & $-0,0517820 * * *$ & $-0,0496492^{* * *}$ & $-0,0835977^{* * *}$ \\
\hline & {$[-3,055]$} & {$[-2,827]$} & {$[-4,014]$} \\
\hline \multirow[t]{2}{*}{ Volatilidade PIB } & $-0,198124$ & $-0,240219^{*}$ & $-0,238434^{*}$ \\
\hline & {$[-1,491]$} & {$[-1,799]$} & {$[-1,842]$} \\
\hline \multirow[t]{2}{*}{ Cresc. Populacional } & $-0,220113$ & $-0,152149$ & $-0,151318$ \\
\hline & {$[-0,9015]$} & {$[-0,6115]$} & {$[-0,6421]$} \\
\hline \multirow[t]{2}{*}{ Capital Humano } & $0,0112971^{*}$ & $0,0129968^{* *}$ & $0,016216^{* * *}$ \\
\hline & {$[1,934]$} & {$[2,082]$} & {$[2,748]$} \\
\hline \multirow[t]{2}{*}{ \% Investim./ PIB } & $0,672884^{* * *}$ & $0,711638^{* * *}$ & $0,545822^{* *}$ \\
\hline & {$[2,720]$} & {$[2,944]$} & {$[2,496]$} \\
\hline \multirow[t]{2}{*}{ Volatilidade Invest. } & $-0,748744$ & $-1,28030^{* *}$ & $-1,05057^{* *}$ \\
\hline & {$[-1,261]$} & {$[-2,310]$} & {$[-2,030]$} \\
\hline \multirow[t]{2}{*}{ \% Despesa/PIB } & $-0,0453083$ & & \\
\hline & {$[-0,2788]$} & & \\
\hline \multirow[t]{2}{*}{ Volatilidade Despesa } & $-0,556695^{*}$ & & \\
\hline & {$[-1,983]$} & & \\
\hline \multirow[t]{2}{*}{ \% Receita/PIB } & & $-0,0573478$ & \\
\hline & & {$[-0,5031]$} & \\
\hline \multirow[t]{2}{*}{ Volatilidade Receita } & & $-0,0205694$ & \\
\hline & & {$[-0,1180]$} & \\
\hline \multirow[t]{2}{*}{ \% Divida Total/PIB } & & & $-0,0901297^{*}$ \\
\hline & & & {$[-1,742]$} \\
\hline \multirow[t]{2}{*}{ Volatilidade Dívida Total } & & & $-0,364535^{*}$ \\
\hline & & & {$[-1,903]$} \\
\hline $\mathrm{N}$ & 135 & 135 & 135 \\
\hline R-Quadrado LSDV & 0,377931 & 0,355601 & 0,394789 \\
\hline Durbin Watson & 2,14648 & 2,148437 & 2,118728 \\
\hline
\end{tabular}

Nota: Em colchetes estão os valores de t. * Para significância a 10\%, ** para significância a 5\% e *** para significância a $1 \%$. 
Tabela A3. Volatilidade das Variáveis dos Estados de Grande Porte

\begin{tabular}{|c|c|c|c|c|}
\hline & Média & Mínimo & Máximo & $\begin{array}{l}\text { Desvio- } \\
\text { Padrão }\end{array}$ \\
\hline \multicolumn{5}{|l|}{ UF com maiores PIB pc } \\
\hline Volatilidade PIB (Filtro HP) & 0,033 & 0,005 & 0,116 & 0,020 \\
\hline Volatilidade Investimento (Filtro HP) & 0,006 & 0,001 & 0,032 & 0,007 \\
\hline Volatilidade Receita Total (Filtro HP) & 0,012 & 0,001 & 0,126 & 0,017 \\
\hline Volatilidade Despesa Total (Filtro HP) & 0,010 & 0,001 & 0,053 & 0,009 \\
\hline Volatilidade Dívida Total (Filtro HP) & 0,010 & 0,001 & 0,027 & 0,006 \\
\hline \multicolumn{5}{|l|}{ UF com menores PIB pc } \\
\hline Volatilidade PIB (Filtro HP) & 0,031 & 0,006 & 0,080 & 0,015 \\
\hline Volatilidade Investimento (Filtro HP) & 0,007 & 0,001 & 0,416 & 0,007 \\
\hline Volatilidade Receita Total (Filtro HP) & 0,013 & 0,002 & 0,063 & 0,011 \\
\hline Volatilidade Despesa Total (Filtro HP) & 0,012 & 0,002 & 0,043 & 0,009 \\
\hline Volatilidade Dívida Total (Filtro HP) & 0,014 & 0,002 & 0,097 & 0,016 \\
\hline
\end{tabular}

Nota: Amostra inclui 65 observações para cada grupo.

\section{Teste de Chow}

Com a aplicação do teste de Chow é possivel antever quebras (falhas) estruturais em determinada variável. Mudanças ou falhas estruturais decorrem de mudanças de comportamento em séries de tempo, ou seja, em períodos em que existam deslocamentos abruptos ou choques. Neste artigo foi investigado a existência de quebras estruturais em 2001, que é o período que deveria apresentar os efeitos da implementação da Lei de Responsabilidade Fiscal aprovadas no ano 2000.

O teste de quebra estrutural considera como teste de hipótese:

$H_{0}$ : Sem falha estrutural (Inexistência de quebra estrutural)

$H_{1}$ : Instabilidade dos coeficientes (existe falha estrutural)

O propósito do teste é analisar o modelo estimado a partir de cada uma das séries, propondo um teste $\mathrm{F}$ para o conjunto de estimadores de cada equação em particular. O teste em particular perfaz-se da seguinte forma:

$$
F=\frac{\left[S Q R-\left(S Q R_{1}+S Q R_{2}\right)\right]}{S Q R_{1}+S Q R_{2}} \frac{[n-2(k+1)]}{k+1}
$$


Portanto, o intuito é separar a amostra de acordo com a quebra estrutural e, em seguida, aplicar o teste F acima observando se os estimadores são ou não significantes.

Tabela A4. Testes de quebra estrutural para os 27 estados da Federação entre os anos de 1996 e 2016

\begin{tabular}{|c|c|}
\hline Estados & Teste de Chow \\
\hline $\mathrm{AC}$ & Estatística de teste: $\mathrm{F}(4,13)=0,735557$ com $\mathrm{p}$-valor $=\mathrm{P}(\mathrm{F}(4,13)>0,735557)=0,583995$ \\
\hline $\mathrm{AL}$ & Estatística de teste: $\mathrm{F}(4,13)=1,3238$ com $\mathrm{p}$-valor $=\mathrm{P}(\mathrm{F}(4,13)>1,3238)=0,312629$ \\
\hline AM & Estatística de teste: $\mathrm{F}(4,13)=1,38248$ com $p$-valor $=\mathrm{P}(\mathrm{F}(4,13)>1,38248)=0,293611$ \\
\hline $\mathrm{AP}$ & Estatística de teste: $F(4,13)=0,240219$ com $p$-valor $=P(F(4,13)>0,240219)=0,910499$ \\
\hline BA & Estatística de teste: $\mathrm{F}(4,13)=0,996414$ com $\mathrm{p}$-valor $=\mathrm{P}(\mathrm{F}(4,13)>0,996414)=0,444012$ \\
\hline $\mathrm{CE}$ & Estatística de teste: $\mathrm{F}(4,13)=2,69708$ com $\mathrm{p}$-valor $=\mathrm{P}(\mathrm{F}(4,13)>2,69708)=0,0777369^{*}$ \\
\hline $\mathrm{DF}$ & Estatística de teste: $\mathrm{F}(4,13)=1,78188$ com $\mathrm{p}$-valor $=\mathrm{P}(\mathrm{F}(4,13)>1,78188)=0,192639$ \\
\hline $\mathrm{ES}$ & Estatística de teste: $\mathrm{F}(4,13)=0,942119$ com $\mathrm{p}$-valor $=\mathrm{P}(\mathrm{F}(4,13)>0,942119)=0,470432$ \\
\hline GO & Estatística de teste: $\mathrm{F}(4,13)=0,678052$ com $\mathrm{p}$-valor $=\mathrm{P}(\mathrm{F}(4,13)>0,678052)=0,619211$ \\
\hline MA & Estatística de teste: $\mathrm{F}(4,13)=2,82102$ com p-valor $=\mathrm{P}(\mathrm{F}(4,13)>2,82102)=0,0692315^{*}$ \\
\hline MG & Estatística de teste: $\mathrm{F}(4,13)=1,31557$ com $\mathrm{p}$-valor $=\mathrm{P}(\mathrm{F}(4,13)>1,31557)=0,315394$ \\
\hline MS & Estatística de teste: $\mathrm{F}(4,13)=0,241791$ com $\mathrm{p}$-valor $=\mathrm{P}(\mathrm{F}(4,13)>0,241791)=0,909547$ \\
\hline MT & Estatística de teste: $F(4,13)=0,170645$ com $p$-valor $=P(F(4,13)>0,170645)=0,949543$ \\
\hline PA & Estatística de teste: $\mathrm{F}(4,13)=0,330154$ com $\mathrm{p}$-valor $=\mathrm{P}(\mathrm{F}(4,13)>0,330154)=0,85279$ \\
\hline PB & Estatística de teste: $\mathrm{F}(4,13)=1,47036$ com $p$-valor $=\mathrm{P}(\mathrm{F}(4,13)>1,47036)=0,267353$ \\
\hline $\mathrm{PE}$ & Estatística de teste: $\mathrm{F}(4,13)=2,60653$ com $\mathrm{p}$-valor $=\mathrm{P}(\mathrm{F}(4,13)>2,60653)=0,0846945^{*}$ \\
\hline PI & Estatística de teste: $\mathrm{F}(4,13)=0,917903$ com $\mathrm{p}$-valor $=\mathrm{P}(\mathrm{F}(4,13)>0,917903)=0,482672$ \\
\hline PR & Estatística de teste: $\mathrm{F}(4,13)=0,927927$ com $\mathrm{p}$-valor $=\mathrm{P}(\mathrm{F}(4,13)>0,927927)=0,477571$ \\
\hline RJ & Estatística de teste: $F(4,13)=2,4229$ com $p$-valor $=P(F(4,13)>2,4229)=0,101055$ \\
\hline $\mathrm{RN}$ & Estatística de teste: $\mathrm{F}(4,13)=4,12509$ com $\mathrm{p}$-valor $=\mathrm{P}(\mathrm{F}(4,13)>4,12509)=0,0225353^{* *}$ \\
\hline $\mathrm{RO}$ & Estatística de teste: $\mathrm{F}(4,13)=0,650604$ com $\mathrm{p}$-valor $=\mathrm{P}(\mathrm{F}(4,13)>0,650604)=0,636529$ \\
\hline $\mathrm{RR}$ & Estatística de teste: $\mathrm{F}(4,13)=0,719868$ com $\mathrm{p}$-valor $=\mathrm{P}(\mathrm{F}(4,13)>0,719868)=0,593455$ \\
\hline RS & Estatística de teste: $\mathrm{F}(4,13)=1,05414$ com $\mathrm{p}$-valor $=\mathrm{P}(\mathrm{F}(4,13)>1,05414)=0,417452$ \\
\hline $\mathrm{SC}$ & Estatística de teste: $F(4,13)=1,50859$ com $p$-valor $=P(F(4,13)>1,50859)=0,256713$ \\
\hline $\mathrm{SE}$ & Estatística de teste: $\mathrm{F}(4,13)=1,01479$ com $\mathrm{p}$-valor $=\mathrm{P}(\mathrm{F}(4,13)>1,01479)=0,435387$ \\
\hline $\mathrm{SP}$ & Estatística de teste: $\mathrm{F}(4,13)=0,672314$ com $\mathrm{p}$-valor $=\mathrm{P}(\mathrm{F}(4,13)>0,672314)=0,622805$ \\
\hline TO & Estatística de teste: $\mathrm{F}(4,13)=0,51846$ com $\mathrm{p}$-valor $=\mathrm{P}(\mathrm{F}(4,13)>0,51846)=0,723796$ \\
\hline
\end{tabular}

Notas: * para significância de 10\%, ** para significância de 5\% e *** para significância de $1 \%$. 